\title{
Ruminant Methane Mitigation- Strategy from Bench Top to Field Condition: A Review
}

Preeti Lakhani , Rajesh Kumar, Jyotsna Madan, Sonia Sindhu

10.18805/ag.R-2152

\begin{abstract}
Economical, eco-friendly, future ready and sustainable livestock production to meet ever growing human population is a daunting task for the animal farming community including scientist. Additionally making a sustainable effort to develop strategies or chain of strategies to combact global warming through manipulating ruminants farming is another growing challenge in the era of alarming global warming situation. Among the causes of global warming, animals particularly ruminants are one of the major contributor of methane. Strategies needed to be developed and implemented in order to rescue earth and its inhabitant from monstrous effect of global warming. Ruminant methane emission is one of the prime factor and steps needed to develop and invention of tools for reducing methane emission from enteric methane production which serves necessary evil of ruminants. Present review aims to explore the advancement achieved in rumen methanogen mitigation methods including its challenges and future prospective in order to make strategy implemented from present bench top to ultimate success in field condition.
\end{abstract}

Key words: Greenhouse gas emissions, Methane, Mitigation, Rumen fermentation.

Global warming is real and showing its catastotrophic effect on earth's environment, including its flora and fauna. Post industrialization era there has been increase in rate of extinction of species to new heights and occurrence of disastrous geological changes on earth due to global warming. Every effort must be made in the direction to content this monstrous effect in order to conserve earth's ecosystem so that it can be habitable to life as rightly said by Paul Carlo "No challenge posses a great threat to future generation than climatic change".

Among green house gases carbondioxide $\left(\mathrm{CO}_{2}\right)$ and methane $\left(\mathrm{CH}_{4}\right)$ are most predominate gases where responsible for $20 \%$ and upto $16 \%$ of total global GHG emissions respectively. Even though emission of methane is fractional in amount, than carbon dioxide, but due to its more respective activity, warming effect and shelf life its effects is more pronounced. The rate of increase in methane production and emission is growing at alarming pace post industrialization and had reached upto approximately 1.8 ppm in present scenario which further is expected to be doubled in just one century i.e. 3.39 ppm by 2100 (IPCC 2007). Methane after discovery by Alessandro Volta has been exploited as a major industrial and domestic fuel source but has also been observed to be nearly 28 times more effective (averaged over 100 years) in trapping infrared radiation than carbon dioxide $\left(\mathrm{CO}_{2}\right)$ thus, becoming a major concern to global warming issue. The concentration in the environment has increased from 750 parts per billion (ppb) at time of Volta to more than $1750 \mathrm{ppb}$ in present time. Even though there are natural sinks on earth to remove methane by oxidation into carbon dioxide $\left(\mathrm{CO}_{2}\right)$ and water $\left(\mathrm{H}_{2} \mathrm{O}\right)$ which have capacity of nearly $536 \mathrm{Tg} \mathrm{CH}_{4}$ per year but leaving around a gap of nearly $38 \mathrm{Tg} \mathrm{CH}_{4}$ per year which is accumulated every year in our atmosphere. Ruminants are one of major contributor and thus potential targets in
Lala Lajpat Rai University of Veterinary and Animal Science,Hisar125 004, Haryana, India.

Corresponding Author: Preeti Lakhani, Department of Veterinary Physiology and Boichemstry, Lala Lajpat Rai University of Veterinary and Animal Science, Hisar-125 004, Haryana, India.

Email: preetilakhani@yahoo.co.in

How to cite this article: Lakhani, P., Kumar, R., Madan, J. and Sindhu, S. (2022). Ruminant Methane Mitigation- Strategy from Bench Top to Field Condition: A Review. Agricultural Reviews. DOI: 10.18805/ag.R-2152

Submitted: 05-01-2021 Accepted: 25-11-2021 Online: 14-02-2022

mitigating strategy for methane production as they contribute nearly $84 \mathrm{Tg}$ methane annually at global level through enteric emission. Methane is produced by methanogens acting as hydrogen ion sink in rumen and this enteric production accounts for more than 80 per cent of the methane produced by the ruminants. Efforts must be made to control it otherwise it can lead to waking up of "sleeping giants of the carbon cycle" found in various geological reserves like frozen methane deposits in arctic ocean and the earth environment breakdown can reach to no return zone. Ruminants can help in imparting its soothing effects on global warming by lowering its contribution through various mitigation efforts. However, mitigation strategies must be made in such a way that it does not affect the ruminant's productivity. This aspect is also important keeping in mind the food security of the world as human population is expected to reach 9 billion by 2050 .

\section{Methanogenesis and ruminant enteric fermentation}

Under natural sources livestock sector, predominately ruminants are one of the major sources where buffalo and cattle predominates methane source in Indian subcontinents and other geographical areas respectively. Buffalo accounts 
for $3.93 \mathrm{MT} / \mathrm{animal} / \mathrm{year}$ emission of methane; responsible for $42 \%$ of the total livestock methane emission in India. Methane production in ruminants is necessary devil needed for maintaining homeostasis inside the rumen ecosystem. As an anaerobic environment inside the rumen is essential to maintain healthy microbiota of ruminant which is very sensitive to any kind of changes in the $\mathrm{pH}$. Since, production of volatile fatty acid (VFA) through fermentation is a major source of energy and as a protein carbon chain provider but also produces hydrogen during fermentation leading to drop in $\mathrm{pH}$ with a potential to disturb homeostasis of animal. Hence an effective hydrogen ion $(\mathrm{H}+)$ management system evolved in rumen by symbiotically placing methanogen as hydrogen sink during evolution of ruminants. Even though these hydrogen sinker's archaebacteria group methanogens cost nearly loss of $8 \%$ of gross energy of ruminants otherwise it can be utilized for animal production and growth. Thus, the very important challenge in methane mitigation strategy is to develop an efficient alternative hydrogen sink in range of 6.4 to 8 or to enhance already available hydrogen sink like propionate production.

Methanogen a group of bacteria utilize carbon dioxide and hydrogen to produce methane and then act as a hydrogen sink.

The enteric methane production in ruminants are also effected by various factors like genetic makeup, feed and environment factors such as season, ambient temperature; diet composition, feeding interval and frequency, feed additives; inflow of saliva, microbial population dynamics and breed. Furthermore, characteristics of Rumen itself like its $\mathrm{pH}$, relative composition of fermented volatile fatty acids, substrates type, rate of fermentation, rumen wall papilla and other factors effecting absorption of VFA, concentration and composition of rumen protozoa and fungi also determine the level of $\mathrm{CH}_{4}$ production. On an average adult cattle and buffalo produces nearly 200-600 liters of methane per day which is 7 and 9 times more than sheep and goats. Studies had shown that the heritability of predicted methane emission is 0.35 and have association with relative feed intake (Breider et al 2019). Similarly breed variations are also found, whereas under similar physiological and mangemental condition jersey breed produce less methane than Bonsmara and Nguni (Grobler et al 2014). Type of roughage supplementation green fodder produces less methane production than straw due to higher acetate production causing imbalance in propionate hydrogen sink indicating ratio of VFA acetate/propionate also has direct implication on methane production. Strategy of feeding can also have detrimental effect as two feed schedule increases methane production per hour without affecting DMI, milk yield and composition changes in significant manner than once a day feeding. Apart from feed and genetic makeup methane production can vary in different months of year indicating effect of season or environment on enteric production. Rumen population dynamics of microorganism also severely affect the methane production). Various feed additive also had been found to affect fermentation pattern and thus directly or indirectly effect methane production. Hence a comprehensive strategy is needed to combact methane production which target effectively to different pathways associated with it in order to reduce this important green house emission from ruminants (Fig 1).

\section{Strategies for mitigating methane emissions}

From the past half centuries various strategies had been formulated and tried to mitigate the methane formation by ruminants to combat its negative effect on the environment without affecting the productivity of the animal. However, most of these studies are till now limited up to lab level with variable degree of success. The alarming situation of global warming has compelled nearly every branch of veterinary science to explore various methods for understanding the physiology behind enteric methane production and steps to augment the emission. Physiologist, nutritionists, mangemental science, bitoechnologist and microbiologists had undergone in solo or in combination various studies in detail and explored application of various anti methanogenic substances and strategies for eco-friendly animal production. These mitigation options can thus be divided in to four major categories includes i) genetic manipulation, ii) feed and fodder management, iii) fermentation and rumen ecosystem alteration and iv) mangemental interventions. Apart from these vaccine development and other biotechnological application had recently been tried to overcome this problem. The present review will focus on discussing all the updated work in the abovesaid categories and will try to formulate a strategy which can be helpful to develop a system for benchtop to field conditions.

\section{Genetic manipulation}

The concept of central dogma of life clearly establishes that every reaction within a living organism is controlled by its genetic formulation directly or indirectly. There are three ways by which genetic alteration can be performed either by selecting low emitter animal, or by inoculating better fermentator gene pool in rumen ecosystem or by producing plant with greater and favorable digestibility and fermentation. Various researches needed to be conducted in areas to find out a genetic linkage which can be solely responsible for reducing methane production directly or proportionately like milk production/ methane unit or live weight gain /methane production, or feed intake/methane production which can lead to reduction in the intensity of methane production without effecting the milk or meat production of the animal. Studies conducted on various breeds had shown difference in methane production rate under similar management indicative explicit role of genetic variation. A study between three breed's i.e. Jersey, Bonsmara and Nguni had showed that significant reduced levels of methane production in jersey as compared to the other two breeds, however, these variations are subjected to type of fodder feed to them, when high tannin fodder is given all breed produce methane at similar level (Grobler et al 2014). Whereas no significan variation were found in 
Holstein-Friesian (HF) and Belgian Blue (BB) heifers per unit DM intake (De Mulder et al. 2018). However breed variation were observed between Highlanders and Texels where former produces lower methane (Zhao et al. (2015). A non significant methane production per unit DMI wereobserved between Scottish Blackface vs. Swaledale $x$ Scottish blackface hoggetts (Zhao et al. 2015), Welsh Mountain vs. Texel cross lambs(Fraser et al. 2015), Scottish Blackface vs. Swaledale x Scottish Blackface ewes (Zhao et al. 2015): Holstein-Friesian vs. Jersey heifers (Richmond et al. (2015). Even though such variation needed to be measured with respect to feed ingredient as some animal may produce lower methane in a typical kind of fodder than other because of differential metagenomics exhibiting in their rumen ecosystem. Therefore, on a larger canvas of study is required not only to identify the most efficient breed in term of methane production. Consequently, a decrease in absolute emissions of enteric $\mathrm{CH}_{4}$ can be expected with improved feed efficiency, but this needs confirmation in additional research using a range of diets to ensure no genotype $x$ environment interaction exists. It will be certainly very helpful in identifying breeds or individual for selection purpose. Report suggest through such selection a reduction of methane production between $11-26 \%$ can be achieved within a decade (De Hass et al 2011).
Similarly, Development of plant species with a genetic manipulation yielding more digestable carbohydrates and lower lignin for fodder production will further help in achieving this novel aim.

\section{Dietary manupilation}

\section{Feed and forage management}

Managing feed and forage can be one of the prime way to not only maintain optimum output in economical way from animal but can also be very helpful $\mathrm{CH}_{4}$ mitigation. It includes various aspects of feed and fodder management like grazing management, harvesting of fodder, timing of harvest, selecting superior digestibility species, time interval of feeding, foragesfeed processing practices and storage of fodder as forage with greater ratio of non-fibre carbohydrates to NDF along with less lignin content leads to favorable organic matter intake and degradation by ruminants, hence, help in reducing the load of methane production. Not only it directly reduce methane production per unit DMI or milk but can also help in providing alternate use of [H] by enhancing propionate in total VFA production Johnson and Johnson (1995). More DMI intake not only increase organic matter degradability but also enhance the rate of passage through rumen giving favorable result. Similarly, animal feed on sorghum forage showed nearly $50 \%$ reduction in methane production across the breed than natural veld grazing and

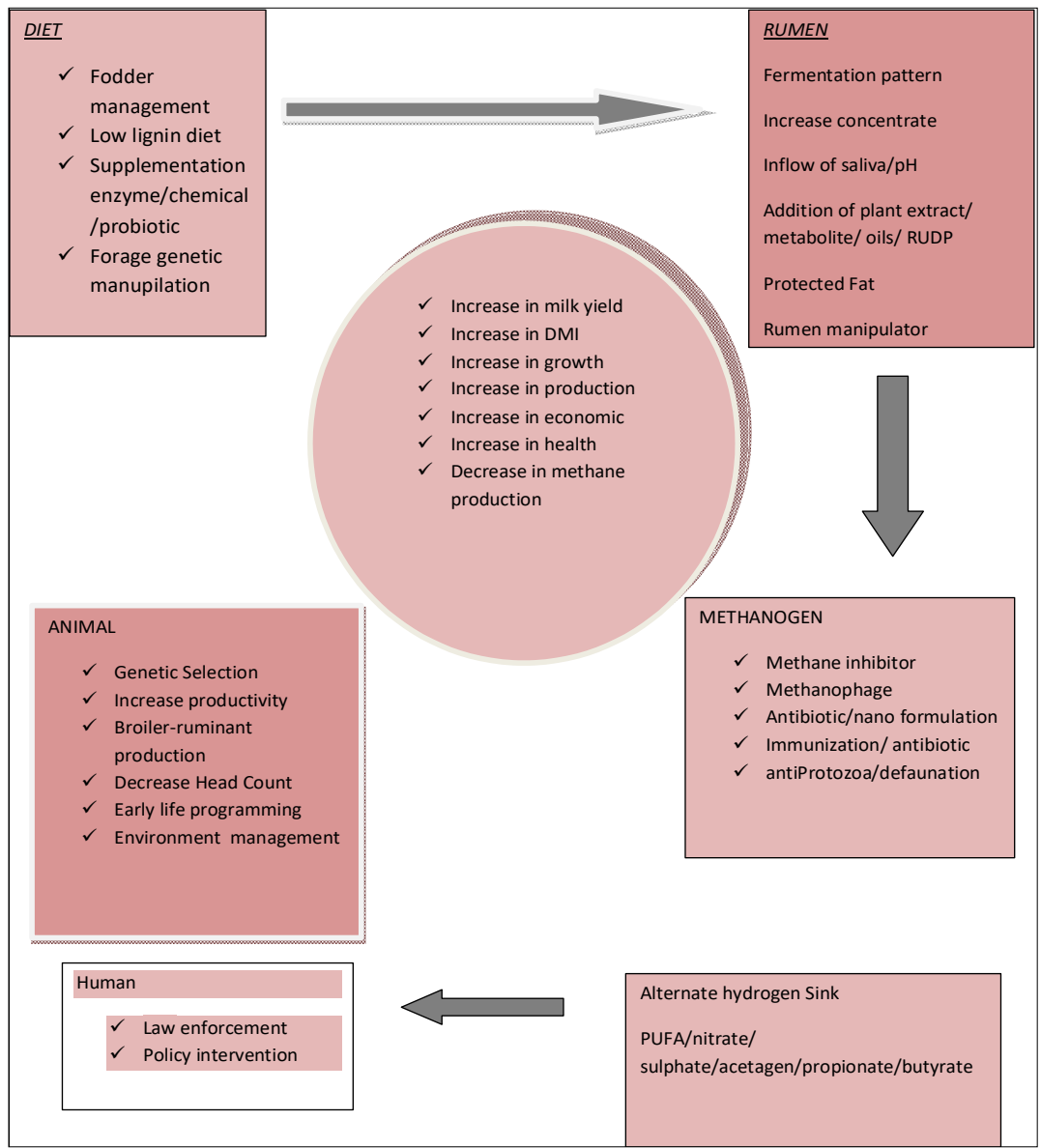

Fig 1: Methane mitigation strategies that can be adopted in field condition. 
oat based pasturelandindicates pasture management can be significant influencer and with higher leguminous fodder will result in methane mitigation (Grobler et al 2014). Similarly cutting the fodder at particular stage of maturity can determine upto $25 \%$ in variability of methane emission where more mature plant lead to more methane production may be due to higher lignifications. Frequency of diet fed to the animal also have determinent effect as feeding once than twice or four times can lead to lower enteric methane without affecting the milk yield (Benchaar and Hassanat 2020). Processing of feed and fodder effecting digestibility like chopping increases surface area making fodder more susceptible for better bacterial attack and mechanical or physical forces like stem or microwave have potential to reduce the lignin content causing faster action by bacteria and greater passage rate through the gut can lead to decrease in methane production. Additionally increase in DMI improves animal productivity to achieve its genetic potential and thus can reduce methane emission by $20-40 \%$ (Johnson et al.,1995). Forages preservation also effect methane production silaging can reduce methane emission upto $33 \%$ as observed in alfalfa silage with respect to alfalfa hay feeding (Benchaar 2002).

\section{Plant extract / metabolites}

Different plant extracts have screened both in vivo and in vitro study for their potential ability to reduce rumen methanogenesis, having compounds like saponins, tannins and essential oils reported to act as natural rumen manipulators. Addition of saponins depending upon the dose and types in the diets has exhibited consistent direct inhibitory effect on rumen protozoa and or methanogenic archaea. Saponins of $\mathrm{S}$. saponaria reduced methane production by $20 \%$ in rusitec (Hess et al. 2002). Agarwal et al. (2000) also reported decline in methane production 96 and $39.4 \%, 20 \%$ respectively with ethanol, water and methanol extracts of S. murkossi, compared with controls. Various saponin rich plant had shown encouraging methane mitigation in rumen like Enterolobium cyclocarpum and Samanea saman (Ku-Vera et al 2020).

\section{Tannins}

Tannins are polymeric compounds formed by oxidation from flavan-3-ol monomers and had showed inhibitory methanogen effects. Similarly, Acacia mearnsii tannin extracts supplimented sheep for 21 days (Carulla et al., 2005) decreased methanogenesis. Among leguminous plants like sulla (Hedysarum coronarium) with higher condensed tannin had shown promising result in methane production without effecting milk contents (Woodward et al 2002). Tannin-containing plants like Leucaena leucocephala when used at $30-35 \%$ of ration dry matter lead to reduction of methane production and disruption of protozoal cell wall (Ku-Vera et al. 2020). Plant tannins act as rumen modifiers modulate rumen fermentation favorably such as reducing protein degradation in the rumen, prevention of bloat, inhibition of methanogenesis and increasing conjugated linoleic acid concentrations therefore have a better acceptance with regard to feed safety issues. Contrary negative impact on feed intake due to astringency and bitterness and a decrease of feed digestibility by tannin nutrient complex formation, rumen enzyme inhibition and growth-inhibition of rumen microorganisms had also been reported (Kumar and Kumar 2014). Further investigation is required to identify the types and doses of tannins that can reduce $\mathrm{CH}_{4}$ without adversely affecting the animal performance properties.

\section{Essential oil}

Studies conducted on essential oils like garlic oil, cinnamaldehyde, eugenol, capsaicin and anise oil, tannins and Eucalyptus leaves results in an inhibition of deamination and methanogenesis, resulting in lower ammonia $\mathrm{N}$, methane and acetate and increase in proportion of propionate and butyrate concentrations acting as an alternate hydrogen sink. However, the effects of some of these essential oils are $\mathrm{pH}$ and diet dependent (Lovett et al., 2015).

\section{Medicinal plant}

Banyan (Ficus benghalensis), Pilkhan (Ficus infectoria), Reetha (Sapindus mukorossi) metha, amla, mint, bel, tulsi, neem and parts there of are important medicinal plant have been identified as potential feed additives to lower methane emission from cattle, sheep and goats (Patra and Saxena 2011). However most of the studies are limited to in vitro fermentation pattern study of various plant metabolites which require animal study to confirm to it.

\section{Feeding concentrates}

Forage based diets which are high in fiber components (i.e cellulose, hemicellulose, lignin) favor the production of acetate and butyrate whereas starch based diets favor production of propionate. Concentrates are rich in easily digestible carbohydrate have direct effect on molar composition on VFA production with enhanced propionate production an effective hydrogen sinker limiting hydrogen availability to methanogens. Furthermore, increase concentrate decreases the ruminal $\mathrm{pH}$ making methanogens more susceptible as archebacteria population decreases sharply when rumen $\mathrm{pH}$ falls below 6.0. (Van Soest et al 1991). Studies had demonstrated that production of $\mathrm{CH} 4$ ceases when $\mathrm{pH}$ of ruminal fluid become $<6.0$ and starts again with return of ruminal $\mathrm{pH}>6.0$, [Van Kessel and Russell (1996)] indicating non destructive suspension of methanogen activity. This clearly signifies the usefulness of total mixed ration (TMR) which had significant benefits like increase in feed intake and digestibility; along with maintaining sufficient fiber intake hence supporting rumen health, like stable ruminal $\mathrm{pH}$, lower $\mathrm{A} / \mathrm{P}$ ratio, maintain rumen papilla size and motility with enhancement of economical production and methane mitigation..Furthermore concentrate rich in Starch elevates $\mathrm{dH}_{2}$ due to faster fermentation than cellulose giving twin benefits of increase milk yield and 
reduced methane production. However, formulation must be made in such a way that rate of fermentation product formation must never exceed the rate of absorption of VFA by rumen as this will eventually lead to subacute or acute ruminal acidosis resulting in negative consequences on animal health and performance.

\section{Supplementation of lipids}

Lipids inhibit methanogenesis by replacing rumen fermentable organic matter in the diet, decreasing the numbers of ruminal methanogens and protozoa and through biohydrogenation of unsaturated fatty acids (Patra, 2013). Biohydrogenation can provide an alternative $[\mathrm{H}]$ sink in the rumen to compete with methanogenesis, Numerous studies reported that low levels of lipid supplementation of diets ( $<4 \%$ of dietary DMI) can decrease $\mathrm{CH}_{4}$ production (by up to $20 \%$, although results are variable) while increasing energy density of diets and benefiting animal productivity in some cases. The results from meta- analysis studies indicate a $1 \%$ to $5 \%$ decrease in $\mathrm{CH}_{4}$ (g/day) per $10 \mathrm{~g} / \mathrm{kg} \mathrm{DM}$ dietary fat ( Patra, 2013) with medium chain $(\mathrm{C} 12: 0, \mathrm{C} 14)$ and polyunsaturated fatty acids being most potent (Patra, 2013), but is often costly and can decrease fiber digestibility and DMI, inhibit rumen fermentation, depress milk fat synthesis and alter the fatty acid composition of products (Patra, 2013). However it requires studies on degree of saturation, amount of fat and the composition of the basal diet and also the stage of lactation in which the fat can be supplemented.

\section{Rumen fermentation manipulator}

Rumen fermentation manipulator like nitrate or sulphate rich compounds have positive effect on animal production by stimulation of favorable fermentation pattern and simultaneously reduction of enteric methane production. Basic strategies which includes increase in DMI or milk yield leading to increase in productivity of the animal, hence, methane production/DMI can be reduced, or by providing alternative hydrogen sink like increase in propionate production which utilize efficiently as hydrogen sink or supplementing nitrate or sulphate rich compounds in the diet or providing PUFA which through biodehydrogenation can utilize hydrogen . All these strategies within physiological limits when used had potential to reduce enteric methane yield without disturbing animal health and production.

\section{Supplementing antimicrobial/antiprotozoal agent in the diet}

Compounds like chloroform, trichloroacetamide and trichloroethyl adipate, bromochloromethane 2-bromoethanesulfonic acid (BES) and Chloral hydrate effectively succeed in methanogen elimination they partially reduce enteric methane production but lead to higher hydrogen content in ruminal eructed gas. Initial analysis of compound rhubarb had antimethanogenic action by blocking methyl-coenzyme $\mathrm{M}$ reductase. Future prospect compounds like 9,10anthracenedione, 1, 8-dihydroxy-3-methyl; phthalic acid isobutyl octadecyl ester and diisooctyl phthalate needed to be verified for its application as an antimethanogenic (Arokiyaraj et al. 2019). Similarly benzylpenicillin and tetracycline reported effective in inhibiting the dung related methanogen inhibiton which can have potential application (Danielsson et al. 2019). lonophores like monensin had showed very encouraging results as antimethanogenic compoundreducing methane production upto $25 \%$. Furthermore, such application needs more comprehensive study and long term studies in term of methane production, animal productivity before commercialization of these compounds as they may cost public health hazard with residual effect and emergence of resistant strain in longer application basis.

\section{Antiprotozoal agents}

Hydrogenosomes a unique organelle present in rumen protozoan associated with hydrogen production through malate oxidization act as a substrate provider to methanogens for their survival. Hence attacking or killing protozoan can be another strategy to combat methane mission. Monensin and other ionophores, are class of drugs that act on protozoan in addition to other pathways had been successful in mitigation of methane upto $25 \%$. But such drugs are banned in countries of Europe keeping in view public health issues. Need of alternative strategies like tea seed saponins had been shown success in selected protozoan inhibition (Cui et al. 2020).

\section{Inclusion of probiotics and fibrolytic enzymes}

Microbial inoculum in feed along with enzymes is another beneficial strategy in altering rumen fermentation pattern and giving twin benefit of higher production and lower methane emission in the animal. Supplementation of fibrolytic enzymes like b-gluconas, xylanase, lysosyme etc. enhance the cell wall digestion rate and can directly or relatively reduce methane production (Biswas et al 2016). Microrganism like Bacillus, Bifidobacterium, Enterococcus, Lactobacillus, Propionibacterium, Megasphaera elsdeniiand Prevotella bryantii and Saccharomyces cerevisia are productivity enhancer through better digestion or utilization of feed stuff or through modulation of wolinellas, Megasphaera ,Fibrobacter and succinate Selenomonas ruminantium etc direct-fed microbials like Lactic Acid Bacteria group like Lactobacillus, together with some species of Enterococcus and Streptococcus or already ruminant inhabitants like Lactobacillus ruminis and Streptococcus equinus, Lactobacillus, and Lactococcus lactis are other alternatives which can be helpful in reduction in methane emission. Lactobacillus pentosus D31 when inoculated with a final dose of $6 \times 10^{10} \mathrm{cfu} /$ animal/day leads to nearly $13 \%$ methane reduction (Jeyanathan et al. 2016). Similarly antimicrobial peptides Bovicins: the bacteriocins of streptococci and their potential in methane mitigation (Hammes et al., 1979) bacteriocins like nisin, catelicidin and bacteria producing bacteroins are another alternative method 
Probiotics like Lactococcus lactis, Peptostreptococcus productus, Streptococcus equinus Bovicin HC5 had shown potential along with ,protease-resistant antimicrobial substances produced by lactic acid bacteria have inhibitory effect on rumen methanogenesis (Garsa et al. 2019).

\section{Use of nano-particles in inhibition of methanognesis}

In the need of the hour role of nanoparticle in ruminant to control methanogen can act as a ray of light in the darkness. Nanoparticles like $\mathrm{ZnO}, \mathrm{CuO}, \mathrm{CoO}, \mathrm{Mn}_{2} \mathrm{O}_{3}, \mathrm{Co}_{3} \mathrm{O}_{4}, \mathrm{Ni}_{2} \mathrm{O}_{3}$ and $\mathrm{Cr}_{2} \mathrm{O}_{3}$, during initial study had shown significant inhibitory effect. Application of AgNPs@10 mg / kg solids strongly inhibited methanogen growth in bioreactors (Garrity, 2001). Similarly application of carbon nanoparticle had been successful in cell lysis of methanogens (Fujinawa et al. 2019). In another study tailored nanoformulation using lytic enyzme, PeiR, had shown 95\% reduction of methane production. The enzyme is produced from virus naturally infecting Methanobrevibacter ruminantium M1 (Altermann et al 2018). There are various NP based strategies which can prove in either immunization by enhancing immune response or using as antibacterial needed to be investigated for methane reduction programme.

\section{Alternative $[\mathrm{H}] 2$ sinks}

Nitrate, sulphate, unsaturated fatty acid and propionate are alternate hydrogen sinker that can be used efficiently in rumen respectively (Lee et al., 2017 and van Zijderveld et al., 2011). Similarly acetogen and sulphate based reduction had also been observed thermodynamically favorable where methane production need $-135.6 \mathrm{KJ}$ they need -104.6 and $15.2 \mathrm{KJ}$ energy respectively as they can be utilized in same molar concentration of hydrogen per mole produced. Expansion of Sulphate-reducing bacteria (SRB) through inoculums supplementation can potentiate the result. However toxicity issues and gaseous hydrogen sulphide eruction must be kept in mind.Supplementation of sulphate at @2.6\% had shown reduction in methane production upto 16\% (van Zijderveld et al., 2010. Similarly reductive actogen produced by numerous bacteria in rumen through acetylCoA pathway fix carbondioxide to acetyl-CoAcan helpful mitigation. This strategy not only provides alternate to methanogenesis but give additional energetic gain benefit to the animal. Inspite of themodynamic favoring methanogen acetogens have $10-100$-fold higher $\mathrm{H} 2$ threshold. Various secondary pathways intermediate of propionate cycle like malate, fumarate, lactate and acrylate if produced economically and supplemented can be effective in increase in production and decrease in methane emission Similarly butyrate enhancers acetoacetate and crotonic acid and 2butynoic acid had been found triumphate in methane reduction (Ungerfeld et al., 2003). Similarly inoculumn of $\mathrm{CH} 4$ oxidizing bacterium native from gut of young pigs, had delivered promising methane mitigators during in vitro trials.

\section{Immunization}

Application of anti-methanogen vaccine and antibody to control enteric methanogens. This new trend have potential to go for selection of better adapted animal and rumen ecosystem in long run. Reduction of methane production rises upto $52 \%$ when vaccine using five strain five Methanobrevibacter spp. strains $1 \mathrm{Y}$ and AK-87, M. millerae ZA-10, Methanomicrobium mobile BP and Methanosphaera stadtmanae MCB-3, had been applied (Williams et al 2009). Similarly vaccine targeting protozoa had also been tried however more trials need to be conducted to validate the success. Development of a commercially successful vaccine with better performance in term of economics, yield and methane reduction is still underway and need more comprehensive research in this promising field (Wedlock et al., 2013).

\section{Managemental strategies}

Animal management along with its optimum production and policy intervention is another way to reduce methane emission from animal which includes new way of animal farming as per requirement of world population and selecting high producing animal by using other interventions.

\section{Early life programming and broiler production}

The pre-weaning diet formulation alters the VFAs fermentation pattern due to modified microbial composition. This provides plasticity nature of ruminal GIT tract which can be employed to get favorable fermentation pattern in terms of production and reduction of emission. The papilla development in early life can be manipulated with pre weaning diet as better development of papilla increase in absorption with increase microbial turnover and thus better production. Scanty data is available for change in size of papillae European breed versus Indian bred which leads to change in propionate efficiency. Stiochiometric alteration of VFA production in through papilla number and size manipulation may be another target in methane reduction programme, apart from size of animal and type of production ultimate (Xiang et al. 2016). It has been observed that fermentation bacteria like Megasphaera, Sharpea and Succinivribrio population and diversity significantly alter with feeding concentrate starter. Similarly diet dependent genera variation in term of dominance of Methanosphaera, Methanobrevibacter, Caecomyces had been observed indicating future potential research area for mitigation of methane (Dias et al 2017).

\section{Broiler calf production}

Another potential application aspect is the naïve concept of broiler calf production. Animal must be demarcated for milk and meat purpose and then farmed accordingly. The study must be performed to understand economically and environmentally viable maximum lactation stages for cattle farming. Similarly we can take a leaf from poultry industry and start developing broiler farms of ruminants for red meat which may not only lesser emission of green house gases but also be economical for meeting future meet demand. We can develop both large and small ruminants like broiler farm where they can be kept for early rumination stage and 
hence get better output of meat with lesser emission. Advent of CRISPER technique can make it more compelling where early programming can be done in future by selecting better growth animal by gene editing of potential gene like myostatin.

\section{Head count reduces methane production}

India has about 512 million livestock which nearly accounts for $17 \%$ of world livestock population. It includes $56.7 \%$ of world's buffaloes, $12.5 \%$ of cattle and $20.4 \%$ small ruminant population and contribute nearly 120 million ton of world total milk production which is 827 million ton. Average milk yield of Indian cattle is $6.2 \mathrm{~kg}$ if successfully increased to 8.0 liters can reduce $32 \%$ head count hence will contribute to $10^{16}$ to $10^{21} \mathrm{kjoule}$ reduction in global warming. Reduction in head count will be very helpful as India account $20 \%$ cattle. An approach targeting increase the animal number in high production group and decreasing the animal number in low production group without affecting the productivity of the milk. This will redce methane emission thus helpful in better resource management positive economic return.

\section{Physical treatment}

Forage based diets which are high in fiber components (i.e. cellulose, hemicelluloses and lignin) favor the production of acetate and butyrate whereas starch based diets favor production of propionate.Therefore, forage based diets are expected to produce more methane than starch based diets. Strategies which enhance digestibility of feed by altering the cell wall composition (reducing hemicelluloses and lignin content) and enhancing the cellulose bio-availability for microbial action are feasible one and this can done by high energy treatment of feed and Microwave based treatment of fodder and cake can be a used as a potential method to break the lignin bond and to make cellulose availability for microbial action in rumen. other methods like grinding and pelleting of forage feed results in increased feed intake and increased rate of passage, can decrease percentage of dietary gross energy (GE) lost as methane by an average of $1.6 \%$ per level of intake.

Microwave based treatment of fodder and cake can be a used as a potential method to break the lignin bond and to make cellulose availability for microbial action in rumen.

Gamma and microwave irradiation as pretreatment to straw had been found to increase ethanol production from cellulosic material including rice straw. We assume that application of gamma irradiation will break the lignin bond and free the cellulose and hemicelluloses for anaerobic fermentation process by bacterial and protozoan inside rumen.

\section{Policy interventions}

Success in prohibiting the growth of emission of greenhouse gases can be achieved through combined efforts and to achieve this success at grass root level needs lot of policy interventions like ETT, Sexed semen and gene edited animal, microbiota of rumen and development of suitable fodder in order to stop the monester of global warming agents and make earth inhibitable. There is need of impetus in research in area of genetic selection through ETT. This require change in policy which can make it possible in field level. Not only research related policies but a collective approach throughout world is required under KYOTO or other similar way for incentivize the farmers for using such technology to make it future ready and sustainable.

\section{Future perspectives}

A comprehensive study is required to investigate full impact of various strategies in solo or in combination to make it realistic and successes in field application as it had been demonstrated that most of the individually strategies resulted in low to moderate $(<20 \%)$ impact or hindrance with other health or production issues during decreasing $\mathrm{CH}_{4}$ emissions. Furthermore a detailed study using recently developed omics techniques including metagenomics, transcriptomics study will decipher microbial interaction under different feeding diet will pave towards economically successful grassroot implantable strategies development. Similarly emphasis on vaccine development, alternate physical treatment like microwave irradiation, finding better genetic animal, microbial population and forage plant or developing them through genetic engineering is a major push area for future research with a practically feasible positive outcome chances. Development of broiler calf and other mangemental intervention study is also the highlight are for future which on one hand can result in methane mitigation while also have potential to fulfill future human requirement in economical way. A strategy or line of assemblances needed to be standardized which includes from animal, fodder and rumen management in comprehensive way for future success.

\section{CONCLUSION}

The efforts done to strengthen the facility to select/adapt and formulate feed supplement for animals which will help in combating methane production as well as improving the productivity of the animal had shown a potential to succeed in mitigating animal methane emission. Research done in field of feed and fodder managements along with various ways to alter rumen fermentation had shown the potential to reduce methane emission from ruminants in practical way. Further advent of various advance technology like ETT, AI, genetic engineering can also strengthen the effort and possibility to increase animal production and productivity thus indirectly assist in this novel cause in major way. All such activity and future research need favorable possible policy setup in order to make this a reality. Research going with a pace and if covered all those grounds as discussed in our review have a realistic potential make it work from 'Bench Top To Field Condition' in near future and eventually helpful in containing global warming.

\section{Declaration of interest}

No conflict of interest among authors. 


\section{ACKNOWLEDGEMENT}

$\mathrm{PL}$ and RK wrote the research article, JM and SS did the final proof reading.

\section{Conflict of interest: None.}

Ethics approval: Not applicable.

Funding: Not applicable.

Availaibility of data and transparency: Not applicable.

\section{REFERENCES}

Agarwal, N., Agarwal, I., Kamra, D.N. and Chaudhary, L.C. (2000). Diurnal variations in the activities of hydrolytic enzymes in different fractions of rumen contents of Murrah Buffalo. Journal of Applied Animal Research. 18(1): 73-80. DOI: 10.1080/09712119.2000.9706325.

Altermann, E., Schofield, L.R., Ronimus, R.S., Beatty, A.K. and Reilly, K. (2018). Inhibition of rumen methanogens by a novel archaeal lytic enzyme displayed on tailored bionanoparticles. Frontiers in Microbiology. 9. DOI:10.3389 /fmicb.2018.02378.

Arokiyaraj, S., Stalin, A. and Shin, H. (2019). Anti-methanogenic effect of rhubarb (Rheum spp.)-An in silico docking studies on methyl-coenzyme M reductase (MCR). Saudi Journal of Biological Sciences. DOI:10.1016/j.sjbs. 2019.06.008.

Benchaar (2002). Evaluation of dietary strategies to reduce methane production in ruminants: A Modelling Approach. Canine Journal Animal Science. 81: 563-574.

Benchaar, C. and Hassanat, F. (2020). Frequency of diet delivery to dairy cows: Effect on nutrient digestion, rumen fermentation, methane production, nitrogen utilization and milk production. Journal of Dairy Science. DOI:10.3168/ jds.2020-18199.

Biswas, A.A., Lee, S.S., Mamuad, L.L., Kim, S.H., Choi, Y.J., Bae, G.S., Lee, K., Sung H.G., Lee, S.S. (2016). Use of Lysozyme as a Feed Additive on In vitro Rumen Fermentation and Methane Emission Asian-Australian Journal Animal Science. 29(11):1601-1607.

Breider, I.S., Wall, E. and Garnsworthy, P.C. (2019). Short communication: Heritability of methane production and genetic correlations with milk yield and body weight in Holstein-Friesian dairy cows. Journal of Dairy Science. DOI:10.3168/jds.2018-15909.

Carulla, J.E., Kreuzer, M., Machmüller, A., and Hess, H.D. (2005). Supplementation of Acacia mearnsiitannins decreases methanogenesis and urinary nitrogen in forage-fed sheep. Australian Journal of Agricultural Research. 56(9): 961. DOI 10.1071/ar05022.

Cui G., Pan C., Xu P., Li Y., Wang, L., and Gong, B. (2020). Purification and Characterization of a Novel Bacteriocin Produced by Enterococcus faecalis CG-9 from Human Saliva. Biotechnology. Biotechnological Equipment. 34 (1): 1224-1233.DOI: 10.1080/13102818.2020.1830714.

Danielsson, R., Lucas, J., Dahlberg, J., Ramin, M., Agenäs, S., Bayat, A.R., Roslin, T. (2019). Compound and contextdependent effects of antibiotics on greenhouse gas emissions from livestock. Royal Society Open Science. 6(10): 182049. DOI:10.1098/rsos.182049.
De Haas, Y., Windig, J.J., Calus, M.P.L., Dijkstra, J., de Haan, M., Bannink, A. and Veerkamp, R.F. (2011). Genetic parameters for predicted methane production and potential for reducing enteric emissions through genomic selection. Journal of Dairy Science. 94(12): 6122-6134. DOI:10.3168/jds.2011-4439.

De Mulder, T., Peiren, N., Vandaele, L., Ruttink, T., De Campeneere, S., Van de Wiele, T. and Goossens, K. (2018). Impact of breed on the rumen microbial community composition and methane emission of Holstein Friesian and Belgian Blue heifers. Livestock Science. 207, 38-44. DOI:10.1016 /j.livsci.2017.11.009.

Dias, J., Marcondes, M.I., Noronha, M.F., Resende, R.T., Machado, F.S., Mantovani, H.C., Suen, G. (2017). Effect of Preweaning Diet on the Ruminal Archaeal, Bacterial and Fungal Communities of Dairy Calves. Frontiers in Microbiology. 8. DOI: 10.3389/fmicb.2017.01553.

Fraser, J., Gupta, R. and Krasny, M.E. (2015). Practitioners' perspectives on the purpose of environmental education. Environmental Education Research. 21(5): 777-800. DOI:10.1080/13504622.2014.933777

Fujinawa, K., Nagoya, M., Kouzuma, A. and Watanabe, K. (2019). Conductive carbon nanoparticles inhibit methanogens and stabilize hydrogen production in microbial electrolysis cells. Applied Microbiology and Biotechnology. DOI:10.1007/ s00253-019-09946-1.

Garrity, G.M., (2001). Bergey's Manual of Systematic Bacteriology: The Archaea and the Deeply Branching and Phototrophic Bacteria. In: [Boone, D.R., Castenholz, R.W. (Eds.)] Second ed. Springer, New York.

Garsa, A.K., Choudhury, P.K., Puniya, A.K., Dhewa, T., Malik, R.K. and Tomar, S.K. (2019). Bovicins: The bacteriocins of streptococci and their potential in methane mitigation. Probiotics Antimicrob Proteins. 11: 1403-1413. doi: 10.1007 Is12602-018-9502-z.

Grobler, S., Scholtz, M., Van Rooyan, H., Mpayipheli, M., and Neser, F. (2014). Methane production in different breeds, grazing different pastures or fed a total mixed ration, as measured by a Laser Methane Detector. South African Journal of Animal Science. 44(5): 12-16. DOI:10.4314/sajas.v44i5.3.

Hess, H., Clemmens, J., Matzke, C.M., Bachand, G.D., Bunker, B.C. and Vogel, V. (2002). Ratchet patterns sort molecular shuttles. Applied Physics A. 75(2), 309-313. DOI:10.1007/s003390201339.

Intergovernmental Panel on Climate Change (IPCC). Climate Change 2007: Synthesis Report. Geneva: IPCC Secretariat.

Jeyanathan, J., Martin, C., Morgavi, D.P. (2016). Screening of bacterial direct-fed microbials for their antimethanogenic potential in vitro and assessment of their effect on ruminal fermentation and microbial profiles in sheep. Journal Animal Science. 94 739-50. DOI:10.2527/jas2015-9682.

Johnson, K.A. and Johnson, D.E. (1995). Methane emissions from cattle. Journal Animal Science. 73: 2483-2492.

Kumar, K. and Kumar, S. (2014). Exploitation of tannins to modulate rumen ecosystem and ruminants performance: A Review The Indian Journal of Animal Sciences. 84(6): 609-618.

Ku-Vera, J.C., Jiménez-Ocampo, R., Valencia-Salazar, S.S., Montoya-Flores, M.D., Molina-Botero, I.C., Arango, J.,and Solorio-Sánchez, F.J. (2020). Role of Secondary Plant Metabolites on Enteric Methane Mitigation in Ruminants. 
Frontiers in Veterinary Science. 7. DOI:10.3389/ fvets.2020.00584.

Lee. C., Araujo, R.C., Koenig, K.M., Beauchemin, K.A. (2017). Effects of encapsulated nitrate on enteric methane production and nitrogen and energy utilization in beef heifers. Journal Animal Science. 99:7898-7903. DOI:10.3168/jds.2016-10910.

Lovett, D.K., Stack, L.J., Lovell, S., Callan, J., Flynn, B., Hawkins, M., O. and Mara, F.P. (2015). Manipulating enteric methane emissions and animal performance of latelactation dairy cows through concentrate supplementation at pasture. Journal Dairy Science. 88, 2836-2842.

Patra, A. and Saxena, A. (2011). Exploitation of dietary tannins to improve rumen metabolism and ruminant nutrition. Journal Science Food Agriculture. 91:24-37.DOI:10.1002/ jsfa.4152.

Patra, A.K. (2013). Meta-analyses of effects of phytochemicals on digestibility and rumen fermentation characteristics associated with methanogenesis. Journal Science Food Agriculture. 90:2700-8. DOI: 10.1002/jsfa.4143.

Richmond, H., Hall, A.M., Copsey, B., Hansen, Z., Williamson, E., Hoxey-Thomas, N. Lamb, S.E. (2015). The Effectiveness of Cognitive Behavioural Treatment for Non-Specific Low Back Pain: A Systematic Review and Meta-Analysis. Plos One. 10(8): e0134192.DOI:10.1371/journal. pone.0134192.

Ungerfeld, E.M. (2003). Inhibition of Rumen Methanogenesis and Ruminant Productivity: A Meta-Analysis. Frontiers in Veterinary Science. 5. DOI:10.3389/fvets.2018.00113.
Van Kessel, J.A.S. and Russell, J.B. 1996. The effect of $\mathrm{pH}$ on ruminal methanogenesis. FEMS Microbiology Ecology. 20:205-210. DOI: 10.1016/0168-6496(96)00030.

Van Zijderveld, S.M., Gerrits, W.J.J., Apajalahti, J.A., Newbold, J.R., Dijkstra J. Leng, R A (2010). Nitrate and sulfate: effective alternative hydrogen sinks for mitigation of ruminal methane production in sheep. Journal Dairy Science. 93:5856-66. DOI:10.3168/jds.2010-3281.

Van Zijdervelt, S.M.J. Gerrits, W.J., J. Dijkstra. and H.B. Pedrock. (2011).Persistency of methane mitigation by dietary nitrate supplementation in dairy cows. Journal Dairy Science. 94(8): 4028-38.doi: 10.3168/jds.2011-4236.

Williams, L., Waghorn G.C., Ulyatt, M.J. and Lassey, K.R. (2009). Early indications that feeding Lotus will reduce methane emissions from ruminants. Proceeding New Zealand Social Animal Production. 61: 23-2.

Woodward, L., Waghorn, G.C., Ulyatt, M.J. and Lassey, K.R. (2002). Early indications that feeding Lotus will reduce methane emissions from ruminants. Proceeding New Zealand Social Animal Production. 61: 23-2.

Xiang, R., Mc Nally, J. and Rowe, S. (2016). Gene network analysis identifies rumen epithelial cell proliferation, differentiation and metabolic pathways perturbed by diet and correlated with methane production. Science Reproduction. 6: 39022. DOI: 10.1038/srep39022.

Zhao, Y.G., Aubry, A., O'Connell, N. E., Annett, R. and Yan, T. (2015). Effects of breed, sex and concentrate supplementation on digestibility, enteric methane emissions and nitrogen utilization efficiency in growing lambs offered fresh grass 1 . Journal of Animal Science. 93(12): 5764-5773. DOI:10.2527/jas.2015-9515. 